\title{
Cognitive Function Study of Chinese and Western Economic Integration Perspective of Intercultural Communication
}

\author{
Tang Ning \\ HeNan Polytechnic 450046 \\ Project number of soft science research project of Henan Province: 162400410329
}

\begin{abstract}
Keywords: economic integration, Chinese and Western cultures, communication
\end{abstract}
\begin{abstract}
As the global economy continues to develop,the process of globalization continues to accelerate the pace of its integration process in accelerating the process of cultural integration efforts and economic cooperation between countries continued to increase, however, but in the development of this stage, there are large differences in the long-term development of Western culture, resulting in the integration process and to promote mutual exchanges, the mutual collision of Chinese and Western card in which economic integration cognitive Perspective function Study of Intercultural communication has a very important significance.

Culture does not exist as an individual characteristics, they represent a common psychological program people living in the same environment to be formed, which contains a lot of upbringing, social experience,etc,it is obvious, because of differences in regional, national,etc, the psychological program inevitably there are some differences. This is a subject to educate them, in the way of work and life are closely related, because they have a different social experience and work history, so it slowly so that they formed a different way of thinking, this is cultural difference ${ }^{[1-2]}$.

With the development of people's daily exchanges of economic integration in the world economy, all countries have different cultural backgrounds are becoming increasingly frequent ${ }^{[3-4]}$. Especially with Chinese implementation of reform and opening up policy, more and more people from western countries into China, but also accompanied by a large number of Chinese residents out of the country, in the process, cross-border, cross-regional, cross-national, cross economic and social and cultural exchanges increasing, which makes our daily lives have contacts and exchanges with the westerners. For this reason, we are in the west different historical and cultural traditions, social customs, religious beliefs and practices, in this process has been fully reflected.
\end{abstract}

\section{The concrete manifestation of cultural differences}

\subsection{The Justice and Profit}

In general, western attache great importance to the interests and light friendship,but Chinese attache great importance to the friendship light the interests or to be balance. Chinese people by the influence of traditional culture, most of the time will subconsciously word meaning head. Chinese history has left us with a lot of the word at the head of the hero role models, such as the TaoYuanSanJieYi of GuanYu, ShuHuiZhuan's LuZhishen pull down willow trees, etc,there are subject to post-Congress appreciated. Relatively speaking, the short history of western culture is more emphasis on benefits, which is the realism of the performance. From the war of aggression against China in modern history and contemporary reality of life in western countries, it can reflect the different levels of their thinking and cultural awareness.

\subsection{The overall and individual}

Generally speaking, the Chinese emphasize holistic and comprehensive, while western emphasis on individuality. For example, comparison of Chinese medicine and western medicine can be seen that Chinese medicine is more emphasis on the whole, in the treatment process often focus on a holistic approach to be reasonable adjustments and western medicine, by contrast, focus on the right medicine for the individual performance characteristics, targeted therapies, although most of the time quick results, but often only partial healing. Similarly, in the course of daily interactions there are also differences between the overall and individual. For example, in the diet, go to a foreigner's house guest for dinner, when the owner is asked to eat Chinese or Western usually will politely say: "casual" or "off with the Lord." This would make foreigners difficult to understand and decide, I do 
not know what to do. Because in the depths of our Chinese thinking, off with the Lord is one of manners, respect for the owner, but Westerners do not think so, this is the difference.

\subsection{Seeking common ground and divergent}

In western culture philosophy, attaches are great importance to diversity, which is Chinese traditional philosophy is a big difference, our country attaches great importance to the traditional concept of Heaven, pay attention to and for you, give a simple example is the following: our country foreigners who thanked the reception,usually say something: reception is very thoughtful, thank you very much and some other words, rarely speak different words, in Chinese minds, which is received by the respect, but in the concept of western countries, would think, different countries, different cultures, there will certainly be different, except that it is not possible a few polite words, no other words; with different that western delegations at the end of the visit to our country, will be combined with their own feelings, give suggestions, especially point out the difference between the two countries, which also reflects, China and western countries in seeking common ground two distinct and divergent characteristics.

\subsection{Thought and expression}

Differences in Western culture, in the thinking and expression embodied in the very obvious, thinking and expression of Chinese people are usually very delicate, whether in ancient China Ethical Code on women, or in some traditional music and dance works which, are very focused and delicate expression of emotion. in addition, our literature is literature and the Western countries have a very big difference, especially Chinese poetry, and foreign literature are very different, our poetry, usually They are only a few short, but the mood and emotion expressed therein indeed very rich, delicate, and this expression is very intuitive and the Western countries is very different.

\section{Analysis of the root causes of cultural differences}

\subsection{The regional environment}

Our Chinese vast is territory, the existing land area of 960 million square kilometers, and also have a vast territorial waters. Distribution of mountains, plateaus, basins, hills, plains and mountains and other landforms complex and diverse, spanning tropical monsoon climate, with a plurality of climate subtropical monsoon climate, temperate monsoon climate, high altitude mountain climate, temperate continental climate. Therefore, in this complex and diverse environment of the Chinese people, lifestyle and customs it produces different and diverse. In extreme low level of productivity, the interaction between the environment and transport due to objective underdeveloped limits almost everywhere in the closed state, so that the respective cultures around the development, different levels, forming a flourishing situation. The topography of Western countries is relatively simple, mostly plain terrain-based, occasionally a little mountain and basins. Although there exists a vast prairie, but a considerable part of the area is surrounded by the sea, so its climate presents significant marine features, little difference. In short, it is the natural environment of the small western regional differences, and therefore culture under such conditions has generated a lot of similarities.

\subsection{Social-economic}

The end result is to bring economic development to change the material conditions, with the rapid development of the world economy, the Chinese and Western cultures are undergoing tremendous change. Before the Industrial Revolution, Chinese social and economic development in Western countries is far, far away in the prehistoric era, Chinese economy has exceeded the then West. In slave and feudal society, Chinese economy is more developed than the West. Especially in the Chinese feudal society highly developed economy, the Chinese history and culture has been fully developed, the emergence of a large number of cultural achievements, has formed a splendid Chinese civilization. However, Western countries after the Industrial Revolution, the economy has been developing rapidly, at a time when China is still in a state of self-sufficiency self-closing, so that the Western economic and cultural advantages to be swapped with each other, China has begun to lag behind Western countries, and the gap is growing, gradually become a vassal of the Western capitalist economy, it has been involved in the world capitalist market. Until the founding of New 
China, the party's leadership, the people of our country through hard work, finally step by step to keep pace with the world economy. The reason lies in the west of the original level of economic development is too low, so that the people of Western countries is difficult to survive, so people racking their brains to develop their economies and seek new breakthroughs, and ultimately through two industrial revolutions in one fell swoop than China. Development of modern Western economic culture is reflected in the practice of the courage, the courage to try and innovation.

\subsection{Cultural heritage}

Chinese cultural history is very long, especially after a long period of feudal society during the dynasties experienced a lot in this process, China's long history and culture not only did not melt, but the constant development and maturity perfect, and gradually formed a kind of cultural form of its own characteristics. In-depth analysis we will find that no matter how the history of China's regime change, the final analysis, the Han Dynasty, which has become a big trend in the development of Chinese history. This is mainly due to the history of the level of economic and cultural development of the Han tend to be far more than the ethnic minority areas, so even if the minority in the Central Plains region to establish a regime, its rulers had to rule according to Han lifestyle, because in the history of development the river, the Han ethnic Chinese culture and has become a subject of China. Tradition and culture of Western countries is quite different, and its cultural heritage in the process of invasion by alien peoples more serious every dynasties are accompanied by the birth of a new culture and wine culture destroyed, can be saved and continue to spread down the little old culture, in this process the original nation status for their own nation and fight for their rights, so that Western culture has no subjectivity, the more is the mixture of cultures and anti-earned, the formation of a diversity and the rights of the Outlook.

\subsection{Religion}

Although there is Christianity, Buddhism, Catholicism, Islam, Taoism and other large religions in the land of China, but China is a country without religious belief, most people believe in religion is for real needs.Therefore, we can not be regarded as a country with a definite religious beliefs. But Western countries is different, people in Western countries is almost everyone has a religion, like Catholicism, Christianity, Islam and other religions are developed in the West land, impact of religion on the people in Western countries can be said to be entrenched. Thus, the Western culture which permeated with strong religious atmosphere.

\subsection{The social structure}

As we all know,we are a country with many ethnic groups 56 national assembly, but the number of ethnic history of our country far more than today. Many of the nation in their historical and cultural development, are successively formed national culture has its own characteristics and regional characteristics. Although with the development of society, and gradually formed a Han Chinese as the main body, but the culture of minorities remains to be retained on the land of China, and out of brilliant flowers. Thus, with respect to a single national culture in Western countries, China's cultural complexity and diversity can imagine.

\section{The impact of cultural differences on Communication}

\subsection{Way of thinking affect language communication}

People of different cultural backgrounds during language communication, tend to make the unconscious from their own cultural perspective to try to figure out and understand each others' intentions and thinking another. It is this misconception, often make verbal communication presents obstacles and difficulties. As the Chinese people in their own way of thinking and expression organize a set of language information is transmitted to the West, but in the West it seems, according to Western culture and way of thinking, but often difficult to understand and comprehend, followed by misunderstandings and ambiguities, some even resulting in conflicts and misunderstandings, resulting in unnecessary trouble and misunderstandings.

\subsection{Expression affect language communication}

Chinese people affected by traditional thinking and culture, the language and article writing process, in order to make the language more clear, vivid, the use of metaphor, parallelism, 
personification, metaphor and other rhetorical devices or fresh, fashionable rhetoric, in words and on sentences, often prefer to choose vivid vocabulary. For example, the lightsome dragon-boats appear on the river as thouh the starus twirlkle in the Milky Way, the richly decorated pleasure boats look like a scene of mirage, the splendid awninss in green gold chain into a palace of crystal, is this a fairyland or a mere dream? After watching,an American journalist thought that is full of hyperbole,incomprehensible, and amusing.For Western readers, because different emotional foundation of differences and reading habits tend to be rhetoric is difficult to accurately grasp and understand, or even be seen as empty verbiage and hype.

\subsection{Words habits affect language communication}

In everyday life, often on terms habits will greatly influence the language of communication. As Western culture has introduced formal presentations and informal presentation of the points, in formal occasions, the general need to add the appropriate title before the name and title, to show courtesy and respect. For example, in the United States, but the average person Mr. collectively, to have the title and status of the person should be added to the title, to show respect. Seen in this light, the English "Mr" and Chinese "sir" is not exactly the same. In Chinese history and culture, "Sir," the term has no derogatory meaning, the opposite is the teacher, senior, highly respected person honorific. Female and sometimes, for those who have respected women scholars or social influence and appeal of Mr. everyone will use the term to refer to as "Mr. SongQingLing", "Mr. BingXin", "Mr. YangJiang,"and so on, to show respect. However, due to different cultural backgrounds, with the Chinese, "Mr." corresponds to the meaning of the English word "Mr", can easily cause misunderstanding.

\section{Conclusion}

Population and cultural influence under the influence of the West, both the common law of human thinking, also has a unique way of thinking and living habits are formed in each region environment. In cross-cultural communication, people tend to subconsciously agree with the same or similar culture itself, which exclude a large country with its own culture and cultural differences, which would produce a communication misunderstandings and jokes. We say in economic globalization and cultural diversity of today, we should be the premise of mutual respect, uphold the principle of seeking common ground, cooperation and friendly exchanges and mutual assistance.

\section{References}

[1] Difference Lanying influence of Chinese and Western cross-cultural communication [J] introduction and advice, 2006 (4): 88-93.

[2] Sun Yaling Cultural Differences in Intercultural Communication and western [J] Wuxi Nanyang College, 2006,5 (3): 67-70.

[3] Powder Metallurgy new intercultural communication [M] Shanghai: harm Foreign Language Education Press, 1997.

[4] Liu Lie study of cross-cultural communication between East and West recognize the difference [J] business perspective, 2008 (10): 173-174. 